BBA 41073

\title{
BICARBONATE EFFECTS ON CHLOROPHYLL $a$ FLUORESCENCE TRANSIENTS IN THE PRESENCE AND THE ABSENCE OF DIURON
}

\author{
WIM F.J. VERMAAS and GOVINDJEE*
}

Departments of Physiology and Biophysics, and Botany, University of Illinois at Urbana-Champaign, 289 Morrill Hall, 505 S. Goodwin Avenue, Urbana, IL 61801 (U.S.A.)

(Received August 7th, 1981)

(Revised manuscript received December 16th, 1981)

Key words: Bicarbonate effect; Fluorescence; Chlorophyll; Photosystem II; Dichlorophenyldimethylurea

We investigated the effect of $\mathrm{HCO}_{3}^{-}$addition to $\mathrm{CO}_{2}$-depleted thylakoids by means of fluorescence techniques. (1) In the presence of diuron (3-(3,4-dichlorophenyl)-1,1-dimethylurea), the net reduction of the primary quinone-type electron acceptor (Q) of Photosystem (PS) II is about 2-times faster in the absence of $\mathrm{HCO}_{3}^{-}$than in its presence, whether normal, heat-treated or $\mathrm{NH}_{2} \mathrm{OH}$-treated samples are used. This effect of $\mathrm{HCO}_{3}^{-}$is, therefore, not on the $\mathrm{O}_{2}$-evolving apparatus. It is, however, interpreted to be due to an influence of $\mathrm{HCO}_{3}^{-}$on the kinetics of the reduction of $Q$, perhaps combined with an effect on the back reaction of $\mathrm{Q}^{-}$ with $P-680^{+}$, the oxidized form of the PS II reaction center chlorophyll $a$. (2) Fluorescence experiments in the absence of diuron indicate that the absence of $\mathrm{HCO}_{3}^{-}$results in a complete block at the quinone level; the area over the fluorescence induction curve in the absence of $\mathrm{HCO}_{3}^{-}$was found to be 2.2-times higher in the absence than in the presence of diuron, pointing to a complete block of $\mathrm{BH}_{2}$ oxidation in the absence of $\mathrm{HCO}_{3}^{-}$. (3) No change in the midpoint potential of $\mathrm{Q}$ is observed when $\mathrm{HCO}_{3}^{-}$is added to $\mathrm{CO}_{2}$-depleted membranes. $\mathrm{HCO}_{3}^{-}$not only has a large (on/off) effect on the reoxidation of $\mathrm{BH}_{2}$, but also a smaller effect between $P-680$ and $Q$. We propose that $\mathrm{HCO}_{3}^{-}$binding to its specific site in the thylakoid membrane results in a conformational change, allowing normal electron transport between the two photosystems.

\section{Introduction}

Warburg and Krippahl [1,2] observed that the Hill reaction with quinone or $\mathrm{Fe}(\mathrm{CN})_{6}^{3-}$ as electron acceptor is dependent on $\mathrm{HCO}_{3}^{-}$. In the absence of $\mathrm{HCO}_{3}^{-}$, a low Hill reaction rate is observed, but the addition of $\mathrm{HCO}_{3}^{-}$results in an enhancement of this activity. (Since it is not yet certain whether $\mathrm{CO}_{2}, \mathrm{HCO}_{3}^{-}$or $\mathrm{CO}_{3}^{2-}$ is responsible for this effect, although some evidence points

\footnotetext{
* To whom correspondence should be addressed. Abbreviations: PS, photosystem; Chl, chlorophyll; diuron, 3(3,4-dichlorophenyl)-1,1-dimethylurea (DCMU).
}

to $\mathrm{HCO}_{3}^{-}$as the 'binding species' [3], we will use ' $\mathrm{HCO}_{3}^{-*}$ ' to designate the species that binds to a specific site in the thylakoid membrane exerting its stimulatory effect on photosynthetic electron transport.) A major site of action of $\mathrm{HCO}_{3}^{-*}$ has been shown to be between $\mathrm{Q}$, the first quinone-type PS II acceptor, and the plastoquinone pool [4]. In the absence of $\mathrm{HCO}_{3}^{-*}$, the oxidation of $\mathrm{Q}^{-}$by $\mathrm{B}$, the quinone-type two-electron gate, is slowed down [5-8], and the rate of $\mathrm{B}^{2-}$ oxidation by plastoquinone is also decreased dramatically $[6,7]$. Although an effect of $\mathrm{HCO}_{3}^{-*}$ on the oxygen-evolving system has been postulated [9-14], most of the evidence obtained thus far points to an $\mathrm{HCO}_{3}^{-*}$ action on the electron-acceptor side of PS 
II $[4,15-18]$. Absence of $\mathrm{HCO}_{3}^{-} *$ not only inhibits electron transport from $\mathrm{Q}^{-}$to plastoquinone, but it also seems to block the diuron-insensitive electron transport from $\mathrm{Q}^{-}$to $\mathrm{C} 400$ [19], a postulated auxiliary PS II acceptor, and to accelerate the $\mathrm{Q}^{-}$ accumulation in the presence of diuron upon illumination as measured by the $\mathrm{Chl} a$ fluorescence induction curve [20]. We confirm the faster $\mathrm{Q}^{-}$ accumulation in the absence of $\mathrm{HCO}_{3}^{-*}$ and in the presence of diuron, and show that this effect is located between the PS II reaction center, $P-680$, and $Q$, and not on the electron-donor side of PS II as was suggested before [20].

The Chl $a$ fluorescence induction curve, monitoring the rate of the reduction of $Q$ ( $Q$ is a fluorescence quencher, whereas $\mathrm{Q}^{-}$is not [21]), has been shown to consist of a sigmoidal fast phase and a slow phase in the presence of diuron [22-25]. This biphasic behavior was interpreted to be the result of a heterogeneity in the environment of PS II reaction centers: certain reaction centers were postulated to be in contact with adjacent PS II reaction centers and with a large number of antenna chlorophyll molecules ( $\alpha$-centers), whereas other PS II reaction centers ( $\beta$-centers) were to have a small absorption cross-section and lack contact with neighboring PS II reaction centers $[25,26]$. In this paper, we have also analyzed the fluorescence induction curve in $\mathrm{CO}_{2}$-depleted thylakoids to see if the absence of $\mathrm{HCO}_{3}^{-*}$ results in a change in the ratio of $\mathrm{Q}$ related to $\alpha$-centers $\left(Q_{\alpha}\right)$ and $Q_{\beta}$.

Furthermore, we show here that in thylakoids thoroughly depleted of $\mathrm{CO}_{2}$, the rise kinetics of fluorescence induction are best explained by a complete block between $\mathrm{Q}$ and plastoquinone. In the absence of $\mathrm{HCO}_{3}^{-*}$ the area over the fluorescence induction curve is a little more than twice as large without than with diuron, and we interpret this as indicating a complete block between $\mathrm{B}^{2-}$ and plastoquinone.

\section{Materials and Methods}

\section{Chloroplast isolation and $\mathrm{CO}_{2}$ depletion}

Chloroplasts were isolated from peas (Pisum sativum), grown at $20^{\circ} \mathrm{C}$, and were broken as described elsewhere [27]. Broken chloroplasts (thylakoids) were stored at $-60^{\circ} \mathrm{C}$. For $\mathrm{CO}_{2}$ de- pletion, if required, thylakoids were thawed and suspended in $\mathrm{CO}_{2}$-free depletion medium under an $\mathrm{N}_{2}$ atmosphere to a chlorophyll concentration of approx. $30 \mu \mathrm{g} / \mathrm{ml}$. $\mathrm{CO}_{2}$-free media and tubes were obtained by bubbling and flushing, respectively, with $\mathrm{N}_{2}$ gas led through a column containing ascarite and soda-lime. The $\mathrm{CO}_{2}$-depletion medium consisted of $50 \mathrm{mM}$ sodium phosphate, $100 \mathrm{mM} \mathrm{HCO} 2 \mathrm{Na}, 100 \mathrm{mM} \mathrm{NaCl}$ and $5 \mathrm{mM}$ $\mathrm{MgCl}_{2}, \mathrm{pH} 5.3\left(\mathrm{HCO}_{2}^{-}\right.$is supposed to bind to the same site as $\mathrm{HCO}_{3}^{-*}[3,4]$ (Good, N., personal communication)). Thylakoids were incubated for $5 \mathrm{~min}$ in the dark at $0^{\circ} \mathrm{C}$ and pelleted $(5 \mathrm{~min}$ at $1000 \times \mathrm{g}$ ). If thoroughly $\mathrm{CO}_{2}$-depleted thylakoids were required, the pellets were washed again in the pH 5.3 medium (twice-washed thylakoids). The thylakoid pellet was resuspended in a $\mathrm{CO}_{2}$-free medium consisting of $50 \mathrm{mM}$ sodium phosphate, $100 \mathrm{mM} \mathrm{HCO} 2 \mathrm{Na}, 100 \mathrm{mM} \mathrm{NaCl}$ and $5 \mathrm{mM}$ $\mathrm{MgCl}_{2}, \mathrm{pH}$ 6.5. Extreme care was taken that the thylakoid suspension was not exposed to a $\mathrm{CO}_{2}$ containing atmosphere. After this treatment, the $\mathrm{Fe}(\mathrm{CN})_{6}^{3-}$ or 2,6-dichlorophenolindophenol Hill reaction was low, whereas after the addition of 10 $\mathrm{mM} \mathrm{NaHCO}$ an at least 8-fold increase in the Hill reaction rate was observed, indicating that this mild $\mathrm{CO}_{2}$ depletion, a modification of the method used by Stemler [28], works just as well as the rather rough methods of $\mathrm{CO}_{2}$ depletion used before $[3,4,20]$. In twice-washed thylakoids, the Hill reaction rate before $\mathrm{HCO}_{3}^{-}$addition was negligible (less than $3 \mu \mathrm{mol} \mathrm{O} / \mathrm{mg} \mathrm{Chl} \mathrm{per} \mathrm{h).}$

We note that even after this mild method of $\mathrm{CO}_{2}$ depletion, the Hill reaction rates after the addition of saturating $\mathrm{HCO}_{3}^{-}$quantities $(10 \mathrm{mM})$ were lower than those in untreated chloroplasts (approx. 50\% of the original rates). This shows that a considerable irreversible inactivation occurs due to the depletion procedure. The same irreversible inactivation was found if thylakoids were washed in $\mathrm{CO}_{2}$-sufficient medium containing 50 $\mathrm{mM}$ sodium phosphate, $200 \mathrm{mM} \mathrm{NaCl}$ and $5 \mathrm{mM}$ $\mathrm{MgCl}_{2}$ (pH 5.3) (Vermaas, W. and Govindjee, unpublished results), indicating that this inactivation is not due to $\mathrm{CO}_{2}$ depletion but to the treatment at low $\mathrm{pH}$ and high salt concentration. The site of this irreversible effect, mainly due to the low $\mathrm{pH}$ treatment, may be electron donation to $P-680^{+}$(cf. Ref. 29). However, to achieve good 
$\mathrm{CO}_{2}$ depletion, such conditions were found to be necessary. Irreversible loss of some electron-transport activity seems to be unavoidable in the $\mathrm{CO}_{2}$-depletion procedure. (However, see also Ref. 14.)

\section{Fluorescence measurements}

Chl $a$ fluorescence induction measurements were made with an instrument slightly modified from that of Munday and Govindjee [30], using chloroplasts that were dark adapted for at least $20 \mathrm{~min}$. Actinic light was provided by a tungsten lamp; this light passed a water bath and Corning glass filters 4-76 and 3-73 before it hit the sample. The intensity of the actinic light (400-700 nm) was measured with an LI 190S Quantum sensor (Lambda Instuments Corp.). The photomultiplier (EMI 9558 B) was shielded from the actinic light by a Corning 2-64 filter and Bausch and Lomb monochromator ( $\lambda 685 \mathrm{~nm}$, band width $12 \mathrm{~nm}$ ). The fluorescence signal was amplified and recorded on a Tektronix 502 oscilloscope equipped with a polaroid camera. When relatively slow (greater than $1 \mathrm{~s}$ ) transients were measured, the amplified photomultiplier signal was monitored with an Esterline Angus recorder. The area over the fluorescence induction curve as a function of time was determined as described by Melis and Homann [25].

In order to avoid 'artifacts' due to differences in dark-adaptation rates in $\mathrm{CO}_{2}$-depleted chloroplasts in the absence and presence of $\mathrm{HCO}_{3}^{-}$[20], addition, if necessary, of $10 \mathrm{mM} \mathrm{NaHCO}$ to $\mathrm{CO}_{2}$-depleted thylakoid samples was made in the dark 1 min before the fluorescence measurement. Therefore, thylakoids were always dark adapted without added $\mathrm{HCO}_{3}^{-}$.

$\mathrm{CO}_{2}$-depletion and fluorescence measurements, made to elucidate the site of $\mathrm{HCO}_{3}^{-*}$ action between $\mathrm{Q}$ and plastoquinone, were performed under $\mathrm{CO}_{2}$-free air instead of $\mathrm{CO}_{2}$-free $\mathrm{N}_{2}$ because it was suggested [20] that anaerobic conditions might decrease the dark-adaptation (oxidation) rate of electron acceptors, for instance the plastoquinone pool.

\section{Redox titrations}

Fluorescence induction measurements as a function of redox potential were performed in the apparatus described above; the sample holder used for the measurements was connected, via a pump, to a large reservoir containing a dark-adapted thylakoid suspension. After flushing the sample holder and the $\mathrm{O}_{2}$-impermeable tubing between sample holder and reservoir with a large volume (approx. $50 \mathrm{ml}$ ) of the thylakoid suspension equlibrated at a certain redox potential, $3 \mathrm{ml}$ of the suspension were allowed to remain in the sample holder; this sample was used for the fluorescence induction measurements. After the measurement, the illuminated sample was removed from the sample holder by a syringe and discarded. Both the sample holder and the reservoir were kept free of $\mathrm{O}_{2}$ and $\mathrm{CO}_{2}$ by flushing with purified $\mathrm{N}_{2}$. Redox mediators (duroquinone, 9,10-anthraquinone-1,5-disulfonate and benzyl viologen) were added to the reservoir to a final concentration of $10 \mu \mathrm{M}$. Reductive titrations were performed by adding small quantities of a freshly prepared dithionite solution to the reservoir. The addition of dithionite did not decrease the $\mathrm{pH}$ by more than 0.2 units. The redox potential was measured by a combination of a calomel and a platinum electrode (Radiometer type K401 and P101, respectively), connected to a Radiometer PHM 63 digital $\mathrm{pH}$ meter. The redox potential of the calomel electrode relative to the standard hydrogen electrode was accepted to be $+244 \mathrm{mV}$. The electrodes were regularly checked using a mixture of $10 \mathrm{mM} \mathrm{K}_{4} \mathrm{Fe}(\mathrm{CN})_{6} / 10 \mathrm{mM} \mathrm{K}_{3} \mathrm{Fe}(\mathrm{CN})_{6}$ in $100 \mathrm{mM} \mathrm{KCl}$. The redox potential for this couple was taken to be $+436 \mathrm{mV}$ [31].

\section{Results}

The influence of $\mathrm{HCO}_{3}^{-*}$ on the $\mathrm{Chl}$ a fluorescence induction kinetics in the presence of diuron

Fig. 1A shows that the absence of $\mathrm{HCO}_{3}^{-}$* leads to a faster accumulation of $\mathrm{Q}^{-}$in thylakoids in the presence of diuron which is in agreement with earlier observations [20]. The initial and the maximal fluorescence yields are the same in the presence and the absence of $\mathrm{HCO}_{3}^{-*}$, indicating that $\mathrm{HCO}_{3}^{-*}$ does not influence the number of active PS II reaction centers. In the presence of diuron the area over the fluorescence rise curve monitors the concentration of $Q$ [32]. We checked to see if the faster rate of reduction of $Q$ involved a change in the biphasic behavior of the fluores- 

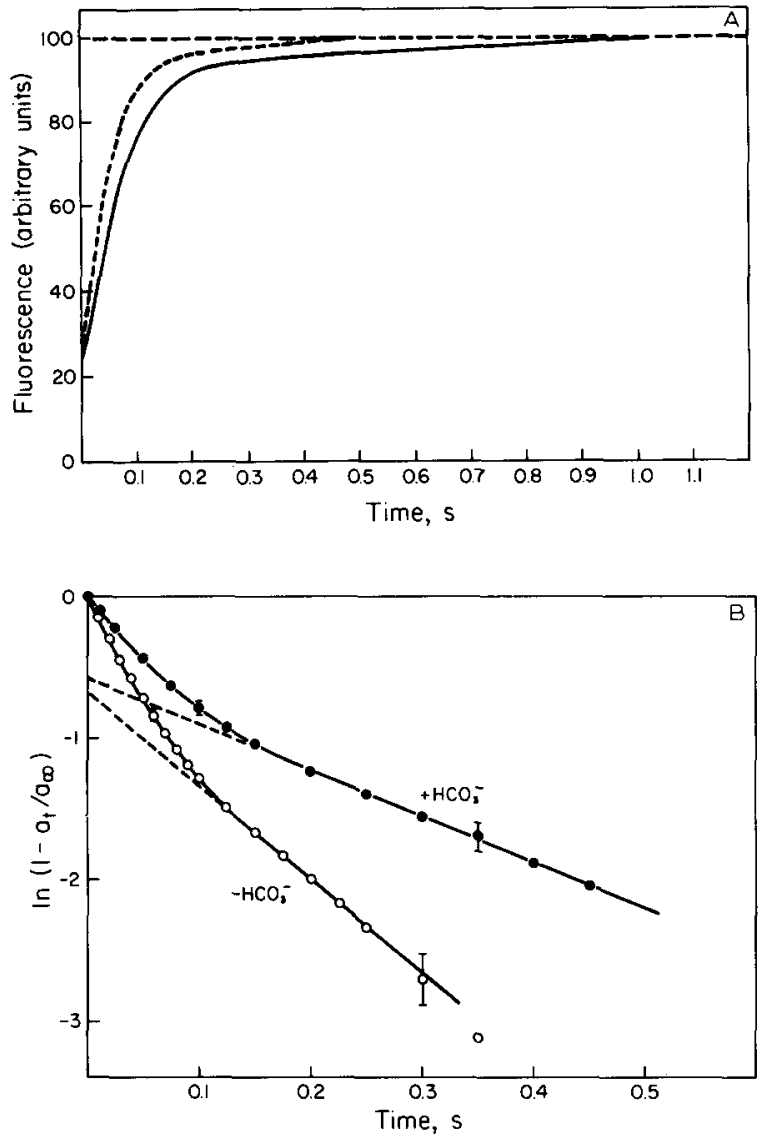

Fig. 1. Chl a fluorescence induction curves of $\mathrm{CO}_{2}$-depleted thylakoids with $10 \mu \mathrm{M}$ diuron in the presence ( $\longrightarrow$ ) or absence (- . - -) of $10 \mathrm{mM} \mathrm{HCO}_{3}^{-}$(A). The natural logarithm of the relative complementary area over the induction curve at time $t\left(\ln \left(1-a_{t} / a_{\infty}\right)\right)$ is calculated at various times for the induction curves with $(\odot)$ and without $(O) \mathrm{HCO}_{3}^{-}$addition and is plotted in $\mathrm{B}$. The light intensity was $15 \mu \mathrm{E} / \mathrm{m}^{2}$ per s; the chlorophyll concentration was $15 \mu \mathrm{g} / \mathrm{ml}$.

cence induction curve. The relative concentration of $\mathrm{Q}$ in its oxidized form at time $t$ was calculated [25] from the ratio $\left(1-a_{t} / a_{\infty}\right)$, in which $a_{t}$ is the area over the fluorescence inducation curve at time $t$ and $a_{\infty}$ is the area at infinite time (all Q reduced). Fig. 1B indicates that the amplitude of the slow phase is somewhat larger after the addition of $\mathrm{HCO}_{3}^{-}$than without $\mathrm{HCO}_{3}^{-}$addition; also, the rate constants of both the slow and fast phases are higher in the absence than in the presence of $\mathrm{HCO}_{3}^{-}$. These differences were observed consistently; the 'tail' in the induction curve was always more pronounced in $+\mathrm{HCO}_{3}^{-}$than in
$-\mathrm{HCO}_{3}^{-*}$ curves. A possible explanation for this phenomenon is that in the absence of $\mathrm{HCO}_{3}^{-*}$ more PS II reaction centers are 'connected' to each other than in its presence.

To locate this $\mathrm{HCO}_{3}^{-*}$ effect in the presence of diuron more precisely, experiments were performed with $\mathrm{CO}_{2}$-depleted thylakoids in which the oxygen-evolving system had been inactivated by mild heat treatment $\left(50^{\circ} \mathrm{C}, 75 \mathrm{~s}\right)$ [33]. Fig. 2A shows that $Q$ reduction in heat-treated $\mathrm{CO}_{2}-$ depleted thylakoids in the presence of an artificial donor $(100 \mu \mathrm{M}$ phenylenediamine $+2 \mathrm{mM}$ ascorbate) is still influenced by $\mathrm{HCO}_{3}^{-}$addition, indicating that the site of this $\mathrm{HCO}_{3}^{-*}$ action is not the oxygen-evolving system. Tris treatment, which
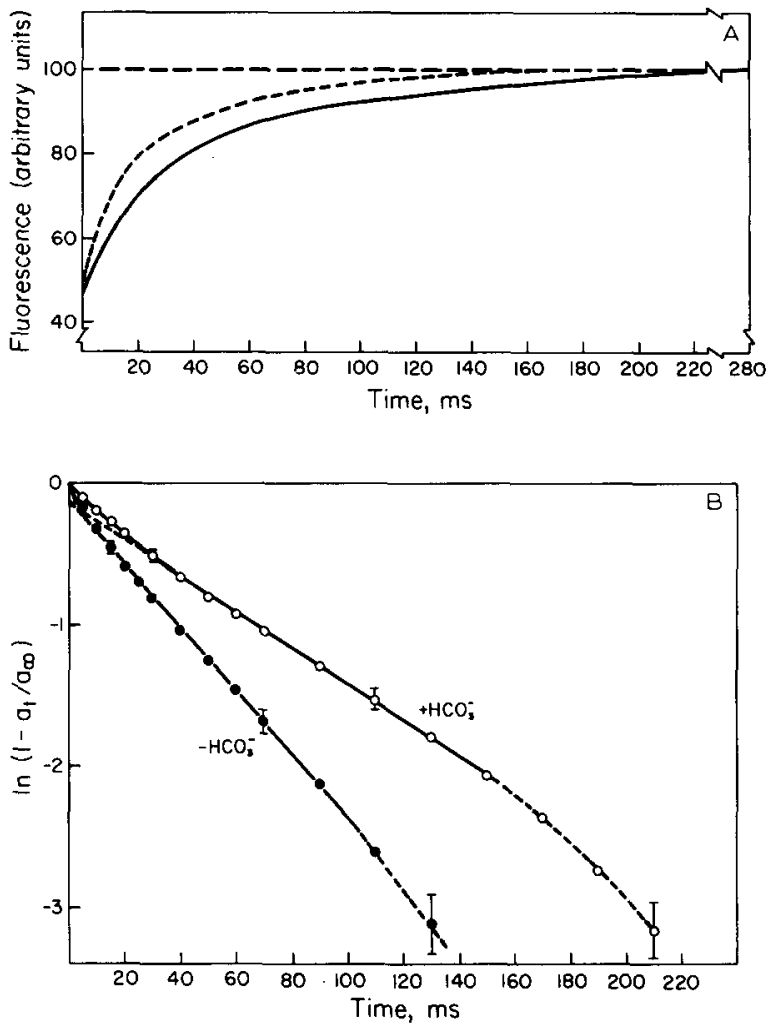

Fig. 2. Chl a fluorescence induction curves of heat-treated $\mathrm{CO}_{2}$-depleted thylakoids with $10 \mu \mathrm{M}$ diuron in the presence $(-)$ or absence $(-.$.$) ) of 10 \mathrm{mM} \mathrm{HCO}_{3}^{-}$(A). The natural logarithm of the complementary area over the induction curve is calculated at various times with (O) and without (O) $\mathrm{HCO}_{3}^{-}$ addition and is plotted in $\mathrm{B}$. Heat treatment: $75 \mathrm{~s}$ at $50^{\circ} \mathrm{C}$; electron donation by $100 \mu \mathrm{M}$ phenylenediamine $+2 \mathrm{mM}$ ascorbate. The light intensity was $15 \mu \mathrm{E} / \mathrm{m}^{2}$ per s; the chlorophyll concentration was $15 \mu \mathrm{g} / \mathrm{ml}$. 
also inactivates the oxygen-evolving system, leads to qualitatively identical results as obtained by heat treatment. After heat treatment the ratio of variable to total fluorescence yield is lowered compared to that of the control, indicating perhaps that certain reaction centers are inactivated resulting in relatively less open traps. This might also explain the faster fluorescence induction $(Q$ reduction) in heat-treated (Fig. 2A) as compared to untreated thylakoids with an intact oxygenevolving system (Fig. 1A). To observe the kinetics of the area growth, a $\ln \left(1-a_{t} / a_{\infty}\right)$ vs. time plot was constructed. As can be seen from Fig. 2B, Q reduction under these conditions became nearly monophasic. The slow phase seems to disappear. This is in agreement with the observation by Thielen and Van Gorkom [34] that in Tris-washed chloroplasts no slow phase is detectable.

It is known [35] that treatment with relatively high concentrations of $\mathrm{NH}_{2} \mathrm{OH}$ (approx. $1 \mathrm{mM}$ ) inhibits the reduction of $P-680^{+}$by its physiological donor, $\mathrm{Z} ; P-680^{+}$is, under those conditions, suggested to be reduced by $\mathrm{NH}_{2} \mathrm{OH}$ via a donor $\mathrm{D}$ [34]. To determine whether $\mathrm{HCO}_{3}^{-*}$ in the presence of diuron acts on $\mathrm{Z}$, the effect of $\mathrm{HCO}_{3}^{-*}$ addition on the fluorescence induction kinetics in $\mathrm{CO}_{2}$-depleted thylakoids was measured after pretreatment with $1 \mathrm{mM} \mathrm{NH} \mathrm{NH}_{2} \mathrm{OH}$ for $5 \mathrm{~min}$ at room temperature. The area over the induction curve of thylakoids in the absence of $\mathrm{HCO}_{3}^{-}$was approx. 1.5-times smaller than that in the presence of $\mathrm{HCO}_{3}^{-}$; the same factor is found in $\mathrm{CO}_{2}$-depleted 'control' thylakoids, i.e., not treated with $\mathrm{NH}_{2} \mathrm{OH}$ (data not shown). This indicates that the observed $\mathrm{HCO}_{3}^{-*}$ action in the presence of diuron is not located at the physiological PS II donor Z.

\section{The midpoint potential of $Q$}

Since most reactions involving $\mathrm{Q}^{-}$reoxidation (i.e., by $\mathrm{B}$, and, probably, $\mathrm{C} 400$ and $P-680^{+}$) seem to be slowed down or blocked in the absence of $\mathrm{HCO}_{3}^{-*}$, it is feasible that the $\mathrm{Q} / \mathrm{Q}^{-}$midpoint potential is influenced by $\mathrm{HCO}_{3}^{-*}$. To check this possibility a redox titration of $Q$ was performed in the region from -20 to $-220 \mathrm{mV}$, without diuron, in the presence and absence of $\mathrm{HCO}_{3}^{-}$ (Fig. 3). (We show only the reductive titration, since the $\mathrm{Q}^{-}$reoxidation under anaerobic conditions was sluggish and incomplete (cf. Ref. 36).)

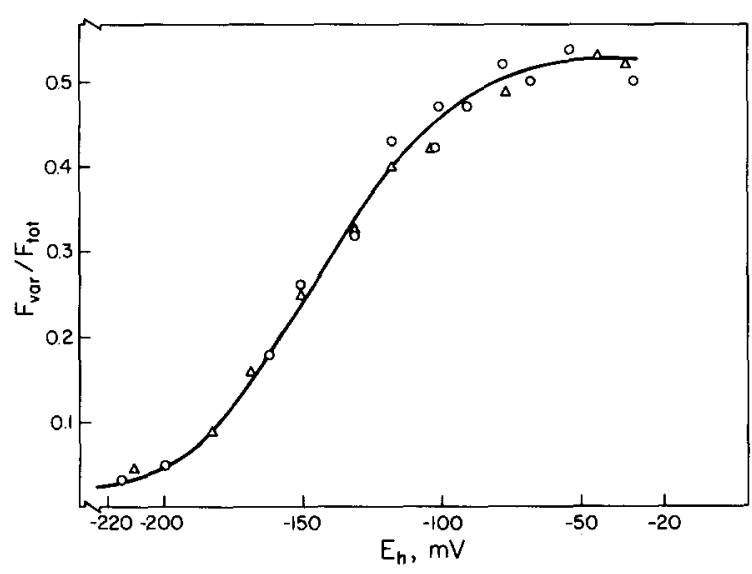

Fig. 3. Titration of the variable $\mathrm{Chl} a$ fluorescence as a function of redox potential in $\mathrm{CO}_{2}$-depleted thylakoids in the presence $(\Delta)$ or absence $(O)$ of $10 \mathrm{mM} \mathrm{HCO}-$. Redox mediators were duroquinone $\left(E_{\mathrm{m}, 7}=+5 \mathrm{mV}\right), 9,10$-anthraquinone-1,5-disulfonate $\left(E_{\mathrm{m}, 7}=-174 \mathrm{mV}\right)$ and benzyl viologen $\left(E_{\mathrm{m}, 7}=-311\right.$ $\mathrm{mV})$, all present at $10 \mu \mathrm{M}$. The chlorophyll concentration was $12 \mu \mathrm{g} / \mathrm{ml}$.

The variable fluorescence disappears almost completely at $-220 \mathrm{mV}$ and a midpoint potential $E_{\mathrm{m}}$ of $-145 \mathrm{mV}(n=1)(\mathrm{pH} \mathrm{6.5})$, both in the absence and in the presence of $\mathrm{HCO}_{3}^{-*}$, is observed. The changes in variable fluorescence as a function of redox potential are not caused by the redox mediators used, since, for instance, omission of 9,10anthraquinone-1,5-disulfonate $\left(E_{\mathrm{m}, 7}=-174 \mathrm{mV}\right)$ does not change the observed pattern (data not shown). The data presented in Fig. 3 indicate that the apparent $E_{\mathrm{m}}$ of $\mathrm{Q} / \mathrm{Q}^{-}$does not change upon $\mathrm{HCO}_{3}^{-}$addition to $\mathrm{CO}_{2}$-depleted thylakoids.

\section{The main site of $\mathrm{HCO}_{3}^{-*}$ action}

In the absence of $\mathrm{HCO}_{3}^{-*}$, the reoxidation of $\mathrm{B}^{2-}$ has been suggested to be influenced more than the reoxidation of $\mathrm{Q}^{-}[6,7]$. However, there is no unambiguous proof for such a statement. It is also not known whether or not the absence of $\mathrm{HCO}_{3}^{-*}$ in a certain photosynthetic chain blocks electron transport completely in that chain (e.g., compare Refs. 7 and 37). To elucidate if the absence of $\mathrm{HCO}_{3}^{-*}$ results in a complete block of electron transfer at the quinone level or only in a slowing down of electron transport, we measured the fluorescence transient in thoroughly $\mathrm{CO}_{2}$ depleted (twice-washed) thylakoids with and without $\mathrm{HCO}_{3}^{-}$addition. In the absence of 


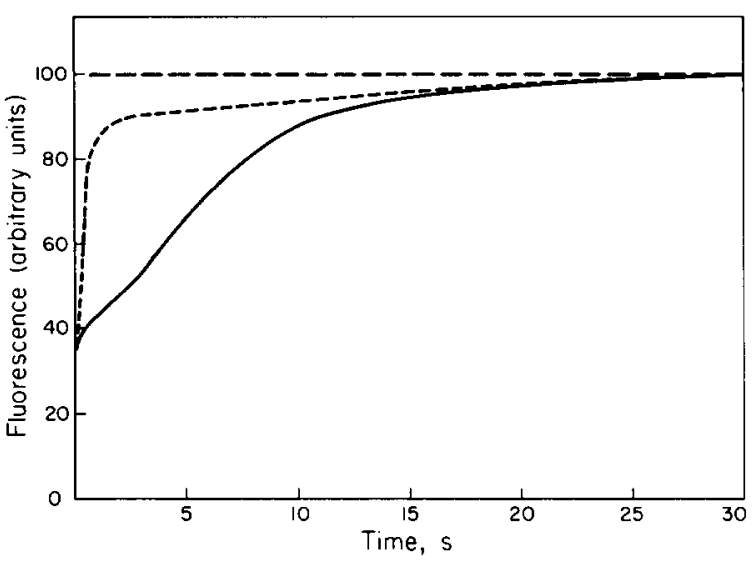

Fig. 4. Chl a fluorescence induction curves of $\mathrm{CO}_{2}$-depleted thylakoids without diuron in the presence (sence (- - - -) of $10 \mathrm{mM} \mathrm{HCO}_{3}^{-}$. The fluorescence intensity at $30 \mathrm{~s}$ has been arbitrarily taken as 100 . The light intensity was approx. $7 \mu \mathrm{E} / \mathrm{m}^{2}$ per $\mathrm{s}$; the chlorophyll concentration was 15 $\mu \mathrm{g} / \mathrm{ml}$.

$\mathrm{HCO}_{3}^{-*}$, the fluorescence level increases fast (similar but not identical to control samples with diuron) to a high level (indicating a rapid accumulation of $\mathrm{Q}^{-}$) followed by a very slow increase (Fig. 4). After the addition of $\mathrm{HCO}_{3}^{-}$a 'normal' fluorescence transient is observed indicating uninhibited electron flow. The tail of this fluorescence induction curve in thylakoids in the presence of $\mathrm{HCO}_{3}^{-*}$ shows the same very slow increase as observed in the absence of $\mathrm{HCO}_{3}^{-*}$ (Fig. 4). Therefore, we suggest that most of this very slow increase in fluorescence yield does not reflect a change in $\left[\mathrm{Q}^{-}\right]$, but is caused by secondary factors influencing the fluorescence yield. Thus, $\mathrm{CO}_{2}$ depletion seems to cause a 'complete' block between $\mathrm{Q}$ and plastoquinone.

Jursinic and Stemler [8] report that the $\mathrm{Q}^{-}$ decay in $\mathrm{CO}_{2}$-depleted thylakoids shows a relatively large amount of a very slow component $\left(t_{1 / 2}=1-2 \mathrm{~s}\right)$. Therefore, we determined whether the major influence of $\mathrm{CO}_{2}$ depletion on fluorescence induction is at the $\mathrm{Q} / \mathrm{B}$ or at the $\mathrm{B} /$ plastoquinone level. Since the area over the fluorescence induction curve is assumed to be proportional to the number of PS II turnovers [38], we compared the areas over the induction curves in thoroughly $\mathrm{CO}_{2}$-depleted thylakoids in the absence and presence of diuron (Fig. 5). Here, the ratio (areadiuron $) /($ area + diuron $)$ is 2.2. This indicates that,

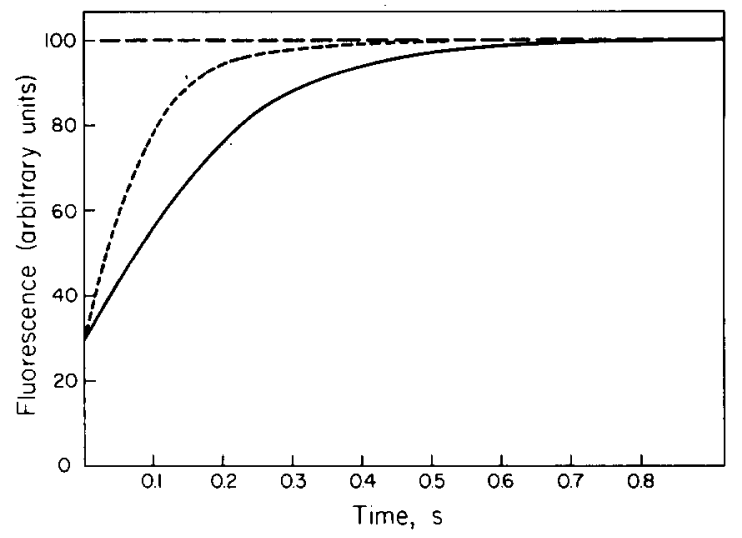

Fig. 5. Chl a fluorescence induction curves of $\mathrm{CO}_{2}$-depleted chloroplasts without (- - ) and with (-...-) the addition of $10 \mu \mathrm{M}$ diuron. The light intensity was $11 \mu \mathrm{E} / \mathrm{m}^{2}$ per $\mathrm{s}$; the chlorophyll concentration was $15 \mu \mathrm{g} / \mathrm{ml}$.

in the absence of $\mathrm{HCO}_{3}^{-*}$ and diuron, $\mathrm{Q}$ and two-electron gate $B$, which is partly in the semiquinone form $\mathrm{B}^{-}$after dark adaptation, can be reduced, whereas in the presence of diuron only $Q$ can be reduced. Therefore, absence of $\mathrm{HCO}_{3}^{-*}$ results in a complete inhibition of $\mathrm{B}^{2-}$ oxidation by plastoquinone.

It should be noted that the thylakoids used in this experiment do not show an appreciable slow phase in the fluorescence induction curve in the presence of diuron (cf. Figs. 1A and 5). A large variability in the ratio of the amplitude of the slow and fast phase appears to exist between different thylakoid preparations.

\section{Discussion}

The rise of the $\mathrm{Chl} a$ fluorescence induction curve in the presence of diuron is faster in the absence of $\mathrm{HCO}_{3}^{-*}$ than in its presence (Figs. 1 and 2); this $\mathrm{HCO}_{3}^{-*}$ effect seems to be located at sites involving $P-680$, pheophytin or $\mathrm{Q}$, since $\mathrm{NH}_{2} \mathrm{OH}$ incubation, known to block electron transport from the physiological donor $\mathrm{Z}$ to $\boldsymbol{P}-680$ [35], does not overcome this effect of $\mathrm{HCO}_{3}^{-*}$. Furthermore, this approx. 2-fold effect is present in heat-treated and Tris-washed thylakoids that have lost the oxygen-evolving reactions. Therefore, it is not possible that this $\mathrm{HCO}_{3}^{-*}$ effect is directly 
involved in oxygen evolution, although other effects of $\mathrm{HCO}_{3}^{-*}$ on oxygen-evolution steps have been suggested by other researchers [10-14]. The observation that the approx. 2-fold difference in fluorescence induction is still present after $\mathrm{NH}_{2} \mathrm{OH}$ treatment rules out the possibility that a difference in the rate of the back reaction between $\mathrm{Q}^{-}$and $P-680^{+}$in the presence and absence of $\mathrm{HCO}_{3}^{-*}$ is the only cause of the $\mathrm{HCO}_{3}^{-*}$ effect on fluorescence induction in the presence of diuron: $\mathrm{NH}_{2} \mathrm{OH}$ is known to slow down that back reaction (e.g. see Ref. 39). Furthermore, the microenvironment of $Q$ does not seem to be sensitive to $\mathrm{HCO}_{3}^{-*}$ : the apparent $E_{\mathrm{m}}$ of $\mathrm{Q} / \mathrm{QH}$ is independent of $\mathrm{HCO}_{3}^{-*}$. Although we find one phase in the redox titration of our samples, $Q$ is normally found to be reduced in a biphasic fashion: one component of $\mathrm{Q}\left(\mathrm{Q}_{\mathrm{L}}\right)$ titrates at $E_{\mathrm{m}} \approx-200 \mathrm{mV}(\mathrm{pH} \mathrm{7})$, the other $\left(\mathrm{Q}_{\mathrm{H}}\right)$ at approx. $-30 \mathrm{mV}(\mathrm{pH} \mathrm{7})[40,41]$. Assuming a $\mathrm{pH}$ dependence of $-60 \mathrm{mV} / \mathrm{pH}$ unit for $\mathrm{Q}_{\mathrm{L}}$ [36], i.e., considering a protonation of $\mathrm{Q}_{\mathrm{L}}^{-}$under these conditions, $Q_{L}$ is expected to titrate at about -170 $\mathrm{mV}$ at $\mathrm{pH} 6.5$, which is rather close to the $E_{\mathrm{m}}$ of $-145 \mathrm{mV}$ (pH 6.5) reported here. We do not speculate at this moment on to the reason why no $\mathrm{Q}_{\mathrm{H}}$ is detected in our samples.

Although the exact origin of the $\mathrm{HCO}_{3}^{-*}$ effect in the presence of diuron has not been found yet, $\mathrm{HCO}_{3}^{-*}$ has an effect, additional to the large one between $\mathrm{BH}_{2}$ and plastoquinone, on the kinetics of $\mathrm{Q}^{-}$formation.

In thylakoids without diuron, the absence of $\mathrm{HCO}_{3}^{-*}$ appears to result in a complete block of the $\mathrm{BH}_{2} \rightarrow$ plastoquinone reaction (Figs. 4 and 5): in the absence of $\mathrm{HCO}_{3}^{-*}$, the ratio of the areas over the fluorescence induction curve in the absence and presence of diuron is 2.2 (Fig. 5). Thus, the plastoquinone pool is not filled, only the $Q$ and B pools are filled. The somewhat low ratio of the areas ( - diuron) $/(+$ diuron) (2.75 would be expected when $75 \%$ of $B$ is in the fully oxidized form after dark adaptation) may be due to the increased amplitude of the slow component of the $\mathrm{Q}^{-}$decay [8]: in the time of the experiment not all $\mathrm{Q}$ may have reduced $\mathrm{B}$ completely, resulting in a somewhat lower area in the absence of diuron on the time scale used, and thus, in a lower ratio of the areas.

At the relatively low light intensity used, it takes approx. $5 \mathrm{~s}$ to fill half of the plastoquinone pool in the presence of $\mathrm{HCO}_{3}^{-*}$ (at $5 \mathrm{~s}$ the area over the fluorescence curve is about half of the total area of the curve; Fig. 4). If we assume that the photochemically active plastoquinone pool consists of approx. 6 plastoquinone molecules per PS II [42] (12 electron equivalents), then once in about $5 / 6 \mathrm{~s}$ (about $0.8 \mathrm{~s}$ ) an electron is transported into the plastoquinone pool. In the absence of $\mathrm{HCO}_{3}^{-*}$, the $\mathrm{Chl} a$ fluorescence rises to its almost maximal value within about $2 \mathrm{~s}$ (Fig. 4), suggesting a very slow (much greater than $0.8 \mathrm{~s}$; it could be of the order of several seconds or, perhaps, minutes) leakage of electrons to the plastoquinone pool; this is much slower than the half-time of approx. $200 \mathrm{~ms}$ suggested earlier from experiments in repetitive flashing light $[6,7]$.

The proposed site of a complete blockage, by the absence of $\mathrm{HCO}_{3}^{-*}$, on the $\mathrm{B}^{2-} \rightarrow$ plastoquinone reaction (Figs. 4 and 5) is rather unique although a total inhibition of electron flow in membranes having no bound $\mathrm{HCO}_{3}^{-*}$ molecule had been suggested earlier [37]. Most inhibitors (e.g., diuron, atrazine and ioxynil) block the $\mathrm{Q}^{-}$ oxidation, whereas others (2,5-dibromo-3-methyl6-isopropyl-1,4-benzoquinone and the dinitrophenyl ether of iodonitrothymol) block the $\mathrm{PQH}_{2}$ oxidation. If we assume that under normal conditions an exchange between $B$ and plastoquinone is possible, then a block of the $\mathrm{BH}_{2}$ oxidation might indicate that $B$ is insulated from the plastoquinone pool in the absence of $\mathrm{HCO}_{3}^{-}$.

A working hypothesis that emerges now is that the absence of $\mathrm{HCO}_{3}^{-*}$ changes the conformation in the $Q / B$ region such that (1) $Q$ becomes 'separated' from B, and (2) B becomes 'insulated' from the plastoquinone pool. A possibility to explain this 'insulation' is that, in the absence of $\mathrm{HCO}_{3}^{-*}$, $\mathrm{BH}_{2}$ has a high affinity for its binding site on the B-binding protein and, thus, is not released and cannot transfer its electrons to the next acceptor. The proposed conformational change caused by binding or release of $\mathrm{HCO}_{3}^{-*}$ is very specific for $\mathrm{HCO}_{3}^{-*}$ : we have found (unpublished results) that neither $\mathrm{HCO}_{3}^{-}$analogs like $\mathrm{HSO}_{3}^{-}$or $\mathrm{HPO}_{3}^{2-}$ nor $\mathrm{CO}_{2}$ analogs like $\mathrm{CS}_{2}$ are able to restore the Hill reaction rate in $\mathrm{CO}_{2}$-depleted chloroplasts. It is already known that $\mathrm{HCO}_{2}^{-}$cannot restore electron transport in $\mathrm{CO}_{2}$-depleted chloroplasts although it 
is supposed to bind to the $\mathrm{HCO}_{3}^{-*}$-binding site $[3,4]$. Therefore, we propose that the 'bicarbonate action' is extremely specific for $\mathrm{HCO}_{3}^{-*}$ (also, see Ref. 43) and that, perhaps, a binding of different groups of the $\mathrm{HCO}_{3}^{-*}$ molecule (e.g., $\mathrm{C}-\mathrm{OH}$ or $\mathrm{C}-\mathrm{O}^{-}$) to different sites at the same time is required for the recovery of electron transport (see also Ref. 3).

\section{Acknowledgements}

We are grateful to Dr. Christa Critchley for a critical reading of the manuscript and to Drs. Pierre Joliot, Jan Amesz and John Whitmarsh for discussions. This work was supported by a grant from the NSF (PCM 7824532).

\section{References}

1 Warburg, O. and Krippahl, G. (1958) Z. Naturforsch. 13b, $509-514$

2 Warburg, O. and Krippahl, G. (1960) Z. Naturforsch. 15b, 367-369

3 Vermaas, W.F.J. and Van Rensen, J.J.S. (1981) Biochim. Biophys. Acta 636, 168-174

4 Khanna, R., Govindjee and Wydrzynski, T. (1977) Biochim. Biophys. Acta 462, 208-214

5 Jursinic, P., Warden, J. and Govindjee (1976) Biochim. Biophys. Acta 440, 322-330

6 Govindjee, Pulles, M.P.J., Govindjee, R., Van Gorkom, H.J. and Duysens, L.N.M. (1976) Biochim. Biophys. Acta 449, 602-605

7 Siggel, U., Khanna, R. Renger, G. and Govindjee (1977) Biochim. Biophys. Acta 462, 196-207

8 Jursinic, P.A. and Stemler, A. (1981) Abstr. 9th Annu. Meet. Am. Soc. Photobiol. WAM-C5, p. 136

9 Stemler, A. (1980) Biochim. Biophys. Acta 593, 103-112

10 Stemler, A. (1981) in Proceedings of the 5th International Congress on Photosynthesis (Akoyunoglou, G., ed.), vol. 2, pp. 389-399, Balaban International Science Service, Philadelphia

11 Stemler, A. (1982) in Photosynthesis: Development, Carbon Metabolism and Plant Productivity (Govindjee, ed.), Academic, New York, in the press

12 Metzner, H., Fischer, K. and Bazlen, O. (1979) Biochim. Biophys. Acta 548, 287-295

13 Metzner, H., Fischer, K. and Bazlen, O. (1981) in Proceedings of the 5th International Congress on Photosynthesis (Akoyunoglou, G., ed.), vol. 2, pp. 375-388, Balaban International Science Service, Philadelphia

14 Fischer, K. and Metzner, H. (1981) Photobiochem. Photobiophys. 2, 133-140

15 Govindjee and Van Rensen, J.J.S. (1978) Biochim. Biophys. Acta 505, 183-213

16 Van Rensen, J.J.S. and Vermaas, W.F.J. (1981) in Proceedings of the Sth International Congress on Photosynthesis
(Akoyunoglou, G. ed.), vol. 2, pp. 151-156, Balaban International Science Service, Philadelphia

17 Vermaas, W.F.J. and Govindjee (1981) Proc. Indian Natl. Sci. Acad. B47, 581-605

18 Vermaas, W.F.J. and Govindjee (1982) in Photosynthesis: Development, Carbon Metabolism and Plant Productivity (Govindjee, ed.), Academic Press, New York, in the press

19 Radmer, R. and Ollinger, O. (1980) FEBS Lett. 110, 57-61

20 Stemler, A. and Govindjee (1974) Photochem. Photobiol. 19, 227-232

21 Duysens, L.N.M. and Sweers, H.E. (1963) in Studies on Microalgae and Photosynthetic Bacteria (Ashida, J., ed.), pp. 353-357, University of Tokyo Press, Tokyo

22 Doschek, W.W. and Kok, B. (1972) Biophys. J. 12, 832-838

23 Melis, A. and Homann, P.H. (1975) Photochem. Photobiol. $19,227-232$

24 Melis, A. and Homann, P.H. (1976) Photochem. Photobiol. 21, 431-437

25 Melis, A. and Homann, P.H. (1978) Arch. Biochem. Biophys. $190,523-530$

26 Melis, A. and Duysens, L.N.M. (1979) Photochem. Photobiol. 29, 373-382

27 Van Rensen, J.J.S., Wong, D. and Govindjee (1978) Z. Naturforsch. 33c, 413-420

28 Stemler, A. (1980) Plant Physiol. 65, 1160-1165

29 Mathis, P. and Paillotin, G. (1981) in The Biochemistry of Plants (Hatch, M.D. and Boardman, N.K., eds.), vol, 8, pp. 98-161, Academic Press, New York

30 Munday, J.C. and Govindjee (1969) in Progress in Photosynthetic Research (Metzner, H., ed.), pp. 913-922, Laupp, Tübingen

31 Bowes, J.M. and Crofts, A.R. (1980) Biochim. Biophys. Acta 590, 373-384

32 Bennoun, P. and Li, Y.-S. (1973) Biochim. Biophys. Acta $292,162-168$

33 Katoh, S. and San Pietro, A. (1967) Arch. Biochem. Biophys. 122, 144-152

34 Thielen, A.P.G.M. and Van Gorkom, H.J. (1980) Abstr. 5th International Congress on Photosynthesis (Akoyunoglou, G., ed.), p. 568, Department of Biology, Nuclear Research Center (Demokritos), Athens

35 Den Haan, G.A., Gorter de Vries, H. and Duysens, L.N.M. (1976) Biochim. Biophys. Acta 430, 265-281

36 Golbeck, J.H. and Kok, B. (1979) Biochim. Biophys. Acta 547, 347-360

37 Khanna, R., Pfister, K., Keresztes, A., Van Rensen, J.J.S. and Govindjee (1981) Biochim. Biophys. Acta 634, 105-116

38 Forbush, B. and Kok, B. (1968) Biochim. Biophys. Acta $162,243-253$

39 Joliot, P. and Joliot, A. (1981) in Proceedings of the 5th International Congress on Photosynthesis (Akoyunoglou, G., ed.), Balaban International Science Service, Philadelphia, in the press

40 Horton, P. and Croze, E. (1979) Biochim. Biophys. Acta $545,188-201$

41 Horton, P. and Naylor, B. (1979) Photobiochem. Photobiophys. 1, 17-23

42 Stiehl, H.H. and Witt, H.T. (1968) Z. Naturforsch. 23b, 220-224

43 Good, N. (1963) Plant Physiol. 38, 298-304 